University of Wollongong

Research Online

Faculty of Engineering - Papers (Archive)

Faculty of Engineering and Information

Sciences

2012

\title{
Magnetovolume effect in Ho2Fe17-xMnx compounds
}

Jianli Wang

University of Wollongong, jianli@uow.edu.au

A J. Studer

Bragg Institute, ANSTO, Menai, NSW, Australia

$S$ J. Kennedy

Bragg Institute, ANSTO, Menai, NSW, Australia

R Zeng

University of Wollongong, rzeng@uow.edu.au

S. X. Dou

University of Wollongong, shi@uow.edu.au

See next page for additional authors

Follow this and additional works at: https://ro.uow.edu.au/engpapers

Part of the Engineering Commons

https://ro.uow.edu.au/engpapers/4846

\section{Recommended Citation}

Wang, Jianli; Studer, A J.; Kennedy, S J.; Zeng, R; Dou, S. X.; and Campbell, S J.: Magnetovolume effect in Ho2Fe17-xMnx compounds 2012.

https://ro.uow.edu.au/engpapers/4846

Research Online is the open access institutional repository for the University of Wollongong. For further information contact the UOW Library: research-pubs@uow.edu.au 


\section{Authors}

Jianli Wang, A J. Studer, S J. Kennedy, R Zeng, S. X. Dou, and S J. Campbell 


\section{AIP Applied Physics}

\section{Magnetovolume effect in Ho2Fe17-xMnx compounds}

J. L. Wang, A. J. Studer, S. J. Kennedy, R. Zeng, S. X. Dou et al.

Citation: J. Appl. Phys. 111, 07 A911 (2012); doi: 10.1063/1.3671422

View online: http://dx.doi.org/10.1063/1.3671422

View Table of Contents: http://jap.aip.org/resource/1/JAPIAU/v111/i7

Published by the American Institute of Physics.

\section{Related Articles}

Prevention of dewetting during annealing of FePt films for bit patterned media applications Appl. Phys. Lett. 101, 092402 (2012)

Tailoring plasmon resonances in the deep-ultraviolet by size-tunable fabrication of aluminum nanostructures Appl. Phys. Lett. 101, 081110 (2012)

Nonadiabatic generation of coherent phonons

J. Chem. Phys. 137, 22A527 (2012)

Laser induced thermal-wave fields in multi-layered spherical solids based on Green function method J. Appl. Phys. 112, 033521 (2012)

Influence of the magnetic field on the plasmonic properties of transparent Ni anti-dot arrays

Appl. Phys. Lett. 101, 063107 (2012)

\section{Additional information on J. Appl. Phys.}

Journal Homepage: http://jap.aip.org/

Journal Information: http://jap.aip.org/about/about_the_journal

Top downloads: http://jap.aip.org/features/most_downloaded

Information for Authors: http://jap.aip.org/authors

\section{ADVERTISEMENT}

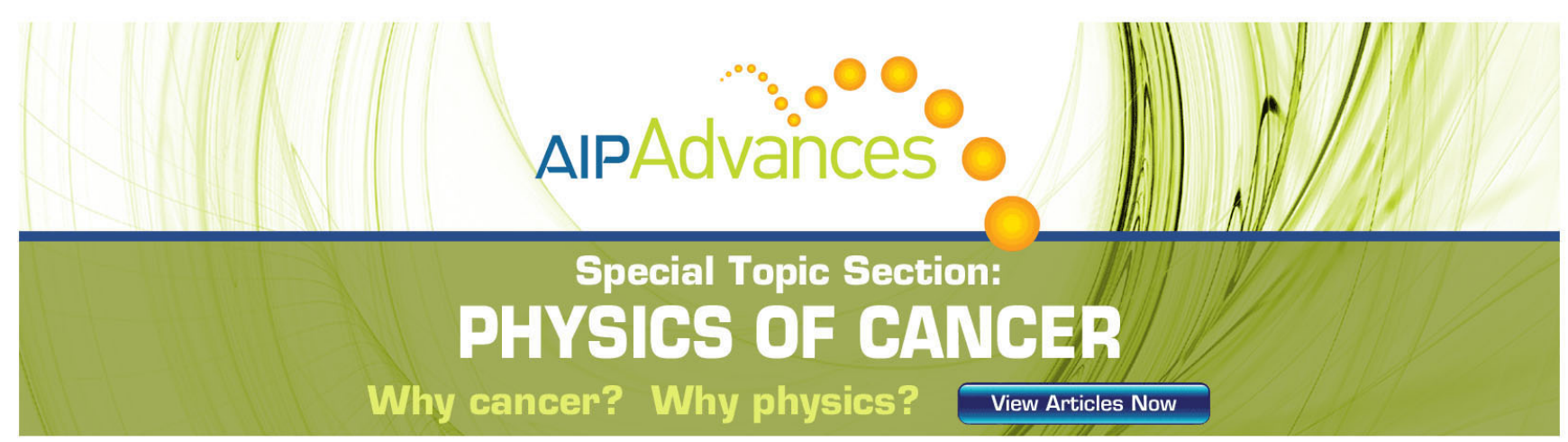




\title{
Magnetovolume effect in $\mathrm{Ho}_{2} \mathrm{Fe}_{17-x} \mathrm{Mn}_{\mathrm{x}}$ compounds
}

\author{
J. L. Wang, ${ }^{1,2,3, a)}$ A. J. Studer, ${ }^{2}$ S. J. Kennedy, ${ }^{2}$ R. Zeng, ${ }^{1}$ S. X. Dou, ${ }^{1}$ and S. J. Campbe $\|^{3}$ \\ ${ }^{1}$ Institute for Superconductivity and Electronic Materials, University of Wollongong, Australia \\ ${ }^{2}$ Bragg Institute, ANSTO, Menai, NSW 2234, Australia \\ ${ }^{3}$ School of Physical, Environmental and Mathematical Sciences, The University of New South Wales, \\ Canberra, ACT 2600, Australia
}

(Presented 31 October 2011; received 26 September 2011; accepted 18 October 2011; published online 13 February 2012)

\begin{abstract}
The structural and magnetic properties of seven compounds in the $\mathrm{Ho}_{2} \mathrm{Fe}_{17-\mathrm{x}} \mathrm{Mn}_{\mathrm{x}}$ series $(\mathrm{x}=0-5)$ have been investigated. The spontaneous magnetization $\mathrm{M}_{\mathrm{s}}$ at $10 \mathrm{~K}$ exhibits a minimum at $x \approx 3.8$ while the $3 d$-sublattice magnetization $\mathrm{M}_{\mathrm{T}}$ is found to decrease at $\sim-3.4 \mu_{\mathrm{B}} /$ per Mn atom compared with the rate of $\sim-2.0 \mu_{\mathrm{B}} /$ per $\mathrm{Mn}$ atom expected from a simple dilution model. All of the $\mathrm{Ho}_{2} \mathrm{Fe}_{17-\mathrm{x}}$ $\mathrm{Mn}_{\mathrm{x}}$ compounds exhibit anisotropic thermal expansion below their Curie temperatures leading to the presence of strong magnetovolume effects and Invar-type behavior below $\mathrm{T}_{\mathrm{C}}$. An approximately zero volume thermal expansion has been detected between $10 \mathrm{~K}$ and $270 \mathrm{~K}$ for $\mathrm{Ho}_{2} \mathrm{Fe}_{17}$. The maximum magnetic entropy changes for $\mathrm{Ho}_{2} \mathrm{Fe}_{17-\mathrm{x}} \mathrm{Mn}_{\mathrm{x}}$ with $\mathrm{x}=0$ and 2.0 are $3.2 \mathrm{~J} \mathrm{~kg}^{-1} \mathrm{~K}^{-1}$ around $\mathrm{T}_{\mathrm{C}} \sim 336 \mathrm{~K}$ and $2.7 \mathrm{~J} \mathrm{~kg}^{-1} \mathrm{~K}^{-1}$ around $\mathrm{T}_{\mathrm{C}} \sim 302 \mathrm{~K}$, respectively, for magnetic field change of B =0-5 T. @ 2012 American Institute of Physics. [doi:10.1063/1.3671422]
\end{abstract}

\section{INTRODUCTION}

Intermetallic compounds $\mathrm{R}_{2} \mathrm{Fe}_{17}(\mathrm{R}=$ rare-earth) with a high concentration of iron continue to attract significant experimental and theoretical interest due to their anomalous magnetic properties. ${ }^{1-3} \mathrm{R}_{2} \mathrm{Fe}_{17}$ compounds crystallize in two related crystal structures, rhombohedral $\mathrm{Th}_{2} \mathrm{Zn}_{17}$ type (light $\mathrm{R}$ ) and hexagonal $\mathrm{Th}_{2} \mathrm{Ni}_{17}$ type (heavy $\mathrm{R}$ ), with the two structures coexisting for some elements in the middle of the lanthanide series. ${ }^{2}$

The $\mathrm{R}_{2} \mathrm{Fe}_{17-\mathrm{x}} \mathrm{Mn}_{\mathrm{x}}$ compounds also continue to attract attention due to their interesting magnetic behavior including a larger magnetovolume effect and the effects of the competition of positive and negative exchange interactions between nearest $\mathrm{Fe}$ atoms. ${ }^{4-6}$ Moreover, as the Curie temperatures of $\mathrm{R}_{2} \mathrm{Fe}_{17}$ are close to room temperature, the magnetocaloric behavior of several $\mathrm{R}_{2} \mathrm{Fe}_{17}$ compounds has been investigated $^{7}$ (e.g., the magnetocaloric effect (MCE) of $\mathrm{Er}_{2} \mathrm{Fe}_{17}$ is $\sim 3.68 \mathrm{~J} / \mathrm{kg} \mathrm{K}$ around $\mathrm{T}_{\mathrm{C}}=294 \mathrm{~K}$ for magnetic field change $\mathrm{B}=0-5 \mathrm{~T}$ ). Here, we investigate the magnetic properties and magnetovolume effect of $\mathrm{Ho}_{2} \mathrm{Fe}_{17-\mathrm{x}} \mathrm{Mn}_{\mathrm{x}}$ compounds with $\mathrm{x}=0.0-5.0$ together with their magnetocaloric behavior.

\section{EXPERIMENTAL PROCEDURES}

$\mathrm{Ho}_{2} \mathrm{Fe}_{17-\mathrm{x}} \mathrm{Mn}_{\mathrm{x}}$ ingots were prepared by arc-melting and annealed at $1000^{\circ} \mathrm{C}$ for a week. Magnetic measurements were carried out over the temperature range $\mathrm{T} \sim 5-350 \mathrm{~K}$ using SQUID (MPMS, quantum design) and Physical Property Measurement System (PPMS). Details of the sample preparation methods and experimental procedures are presented elsewhere. ${ }^{8}$ Neutron powder diffraction experiments $(\lambda=2.4191 \AA$ ) have been carried out from 10 to $450 \mathrm{~K}$ using the high intensity powder diffractometer Wombat, OPAL,

\footnotetext{
a) Author to whom correspondence should be addressed. Electronic mail: jianli@uow.edu.au.
}

Australia. ${ }^{9}$ Two series of variable temperature neutron diffraction measurements were undertaken on each sample after first cooling to base temperature $\mathrm{T}=10 \mathrm{~K}$. The samples were initially investigated using a ramp sequence with a step of $1 \mathrm{~K}$ and counting time of $1 \mathrm{~min}$ at each temperature; this enabled the overall trends of the peak intensities and magnetic transitions to be delineated. The second series $(T=10$ $\mathrm{K}, 100 \mathrm{~K}, 200 \mathrm{~K}, 300 \mathrm{~K}, 400 \mathrm{~K}$, and $450 \mathrm{~K}$; counting time $\geq 10 \mathrm{~min}$ ) provided statistically high quality data for Rietveld refinements. The diffraction patterns were analyzed with the Fullprof package.

\section{RESULTS AND DISCUSSION}

The magnetization curves of free powder samples of $\mathrm{Ho}_{2} \mathrm{Fe}_{17-\mathrm{x}} \mathrm{Mn}_{\mathrm{x}}$ at $10 \mathrm{~K}$ are shown in Fig. 1(a) with the dependence of the spontaneous magnetization $M_{s}(10 \mathrm{~K})$ on Mn concentration shown in Fig. 1(b) $\left(M_{s}\right.$ is derived in the standard way by extrapolation to zero field). $M_{s}$ for $\mathrm{Ho}_{2} \mathrm{Fe}_{17-\mathrm{x}} \mathrm{Mn}_{\mathrm{x}}$ decreases with increasing $\mathrm{Mn}$ content to $\mathrm{x} \approx 3.8$ before increasing with further increase in $\mathrm{Mn}$ content. $\mathrm{Ho}_{2} \mathrm{Fe}_{17}$ is a collinear ferrimagnetic ${ }^{2}$ and the appearance of this minimum in the $M_{s}$ versus x curve can be understood in terms of a compensation concentration originating from the ferrimagnetic coupling between the Ho-sublattice magnetization and the $3 d$ sublattice magnetization. $\mathrm{In}_{\mathrm{Ho}} \mathrm{Fe}_{17}$, the magnetic moments of the Fe ions in all crystallographic positions are collinear to each other but antiparallel to the magnetic moments of the Ho-sublattice. $^{2}$ We have calculated the transition-metal sublattice magnetization $M_{\mathrm{T}}$ from the measured $M_{s}$ by subtracting the Ho-sublattice magnetization (we assume that the Ho sublattice magnetization is the same for all compounds and has the same value, $10 \mu_{\mathrm{B}}$, as the free ion magnetic moment). As shown in Fig. 1(b), the calculated $M_{\mathrm{T}}$ values decrease with Mn content $x$ with the full line representing a linear fit of $\mathrm{M}_{\mathrm{T}}$. A second calculation of the compositional dependence of $M_{T}$ based on a 


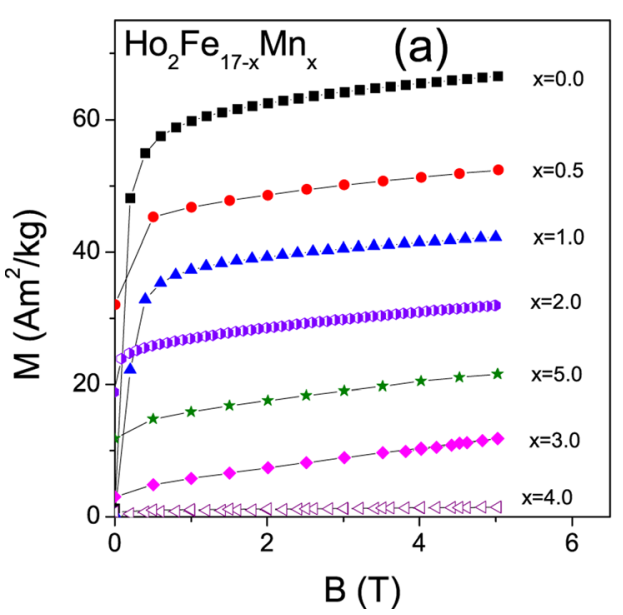

simple dilution model, in which the Mn atoms do not have a magnetic moment, is also shown for comparison (dashed line, Fig. 1(b)). The decrease of $M_{\mathrm{T}}$ with increasing Mn content ( $\sim 3.4 \mu_{\mathrm{B}} /$ per Mn atom) compared with that expected from the dilution model $\left(\sim-2.0 \mu_{\mathrm{B}} /\right.$ per Mn atom) indicates that $\mathrm{Mn}$ atoms have a magnetic moment which is aligned antiparallel to the Fe moments. Similar behaviors have been found for $\mathrm{Tb}_{2} \mathrm{Fe}_{17-\mathrm{x}} \mathrm{Mn}_{\mathrm{x}},{ }^{10} \mathrm{Er}_{2} \mathrm{Fe}_{17-\mathrm{x}} \mathrm{Mn}_{\mathrm{x}},{ }^{11}$ and $\mathrm{Dy}_{2} \mathrm{Fe}_{17-\mathrm{x}} \mathrm{Mn}_{\mathrm{x}}$. ${ }^{5}$

We have investigated the Invar-type anomaly in $\mathrm{Ho}_{2} \mathrm{Fe}_{17-\mathrm{x}} \mathrm{Mn}_{\mathrm{x}}$ by a combination of conventional fixed temperature neutron diffraction patterns and the ramp sequence as described above. As shown for the example of $\mathrm{Ho}_{2} \mathrm{Fe}_{17}$ (Fig. 2; for clarity only the patterns taken at $10 \mathrm{~K}$ steps are shown), the changes in magnetic peak intensities with temperature (inset of Fig. 2) lead to a magnetic transition temperature that agrees well with our magnetic data. ${ }^{8}$ Figure 3 shows the temperature dependence of the volume expansion $\Delta V / V$ for the $\mathrm{Ho}_{2} \mathrm{Fe}_{17-\mathrm{x}} \mathrm{Mn}_{\mathrm{x}}$ compounds of $T_{C}$ values close to room temperature (the lattice parameters were derived from the ramp data using the Le Bail approach; detailed refinements will be presented elsewhere ${ }^{12}$ ). Figure 3 reveals that the $\Delta V / V$ values for all samples tend toward linear behavior at high temperatures above $\mathrm{T}_{\mathrm{C}}$, whereas pronounced Invartype behavior is observed below $\mathrm{T}_{\mathrm{C}}$.

The magnetic contribution to the thermal expansion which gives rise to Invar behavior can be obtained by comparing the experimental results with, $(\Delta V / V)_{\text {latt }}$, the lattice contribution to the volume. We have calculated $(\Delta V / V)_{\text {latt }}$

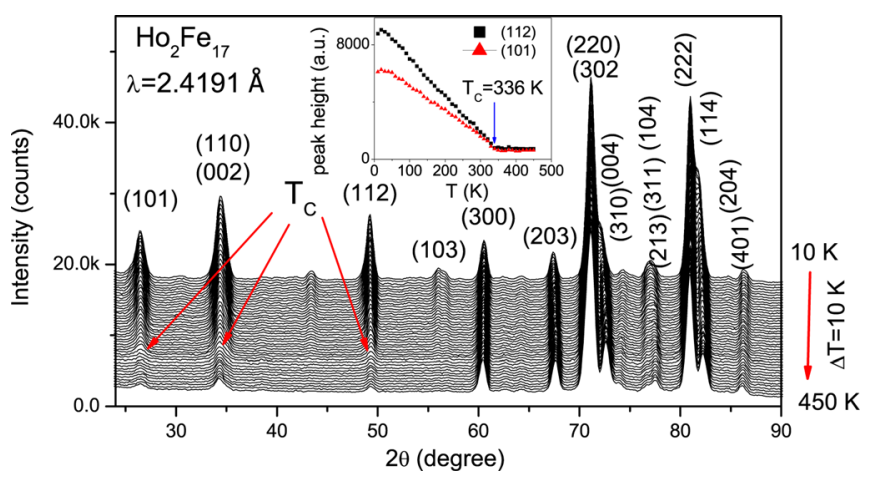

FIG. 2. (Color online) Representative neutron diffraction patterns for $\mathrm{Ho}_{2} \mathrm{Fe}_{17}$ at $10 \mathrm{~K}$ intervals $(\lambda=2.4191 \AA)$. The inset shows a graph of the peak height vs temperature for the (101) and (112) peaks. from the Grüneisen relation using a Debye temperature of $\theta_{D}=450 \mathrm{~K} .^{5,11}$ The thermal dependence of $(\Delta V / V)_{\text {latt }}$ was fitted to the experimental results in the paramagnetic regime leading to the extrapolations shown by the dashed lines in Fig. 3. The deviations from the calculated nonmagnetic anharmonic phonon contributions above $T_{C}$ reveal contributions to the spontaneous magnetostriction even in the paramagnetic phase, indicating the existence of strong short range magnetic correlations above $T_{C} \cdot{ }^{12}$ In the case of $\mathrm{Ho}_{2} \mathrm{Fe}_{17}$, this anisotropic thermal expansion (inset to Fig. 3) leads to approximately zero volume thermal expansion with negligible volume change between $10 \mathrm{~K}$ and $270 \mathrm{~K}$ as shown in Fig. 3.

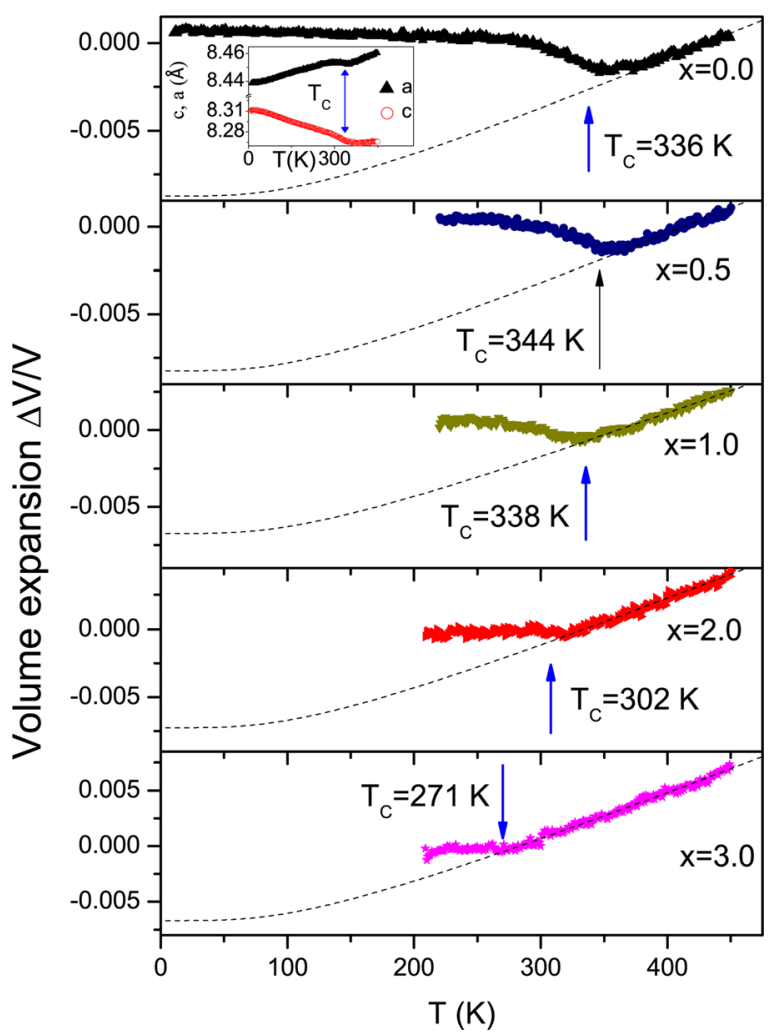

FIG. 3. (Color online) Volume expansion, $\Delta V / V$, for $\mathrm{Ho}_{2} \mathrm{Fe}_{17-\mathrm{x}} \mathrm{Mn}_{\mathrm{x}}$ $(x=0.0-3.0)$ as a function of temperature. The dashed line represents the calculated nonmagnetic anharmonic phonon contribution. The inset shows the a (closed symbols) and c (open symbols) lattice parameters vs temperature for $\mathrm{Ho}_{2} \mathrm{Fe}_{17}$. 


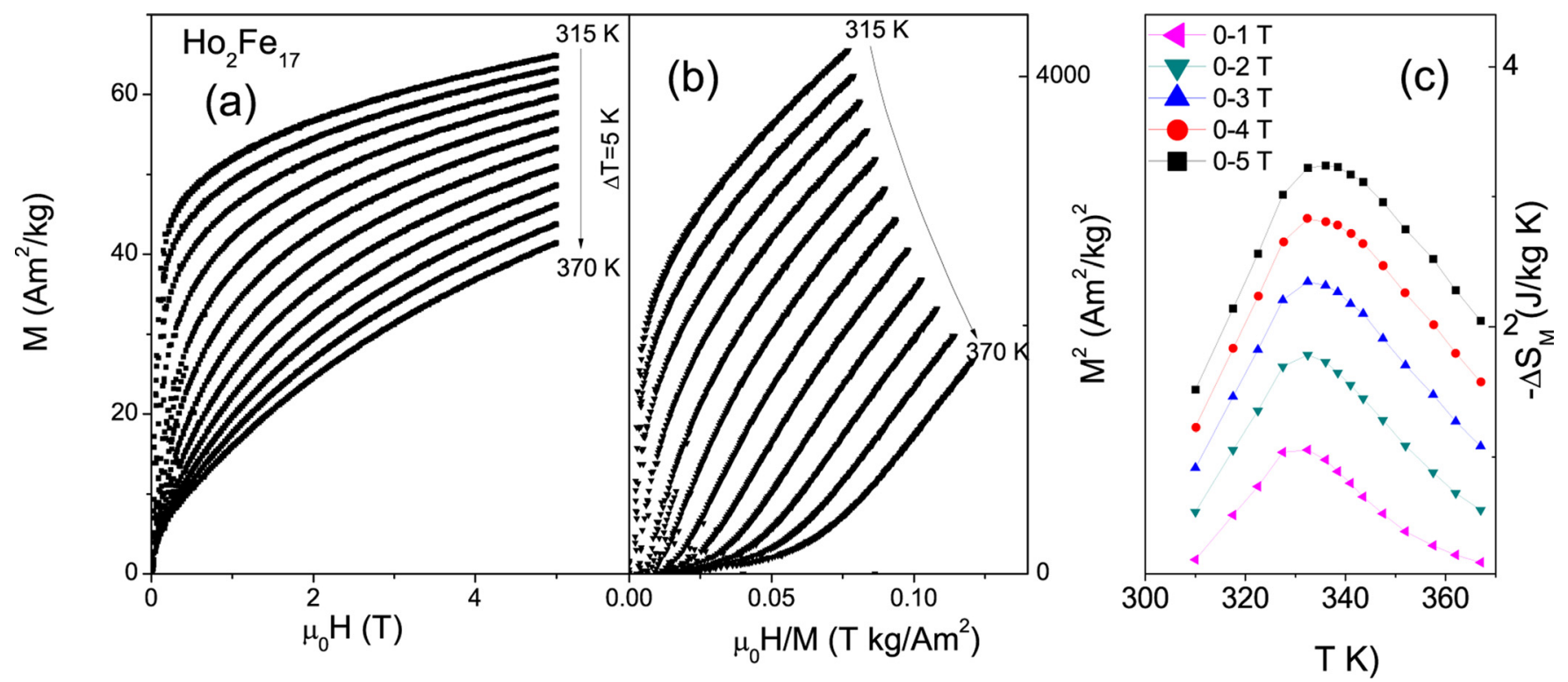

FIG. 4. (Color online) (a) Magnetization as a function of applied DC field $\left(\mu_{0} \mathrm{H}=0-5 \mathrm{~T}\right)$ for $\mathrm{Ho}_{2} \mathrm{Fe}_{17}$ around $\mathrm{T}_{\mathrm{C}} \sim 336 \mathrm{~K}$. (b) Arrot-plots of $M^{2}$ as a function of $\mu_{0} H / M$ for the magnetization data of (a). The positive slopes indicate that the transition at $\mathrm{T}_{\mathrm{C}}$ is second-order. (c) Temperature dependence of the isothermal magnetic entropy change $-\Delta S_{M}(T, \mathrm{H})$ as measured in magnetic fields up to $5 \mathrm{~T}$ and derived from the magnetic data of $4(\mathrm{a})$.

The existence of the Invar effect is related to the strong dependence of $\mathrm{T}_{\mathrm{C}}$ and the magnetization on the interatomic distances. A pronounced decrease of spontaneous magnetization and Curie temperature of $\mathrm{R}_{2} \mathrm{Fe}_{17}$ intermetallic compounds with applied pressure has been reported $(\mathrm{dM} /$ $\mathrm{dp}=-0.1 \mu_{\mathrm{B}} /$ f.u. per kbar for $\mathrm{Ho}_{2} \mathrm{Fe}_{17}$ (Ref. 13) and $\mathrm{dT}_{\mathrm{C}} /$ $\mathrm{dp}=-9.8 \mathrm{~K} / \mathrm{kbar}$ for $\mathrm{Y}_{2} \mathrm{Fe}_{17}$ (Ref. 14)), thus confirming the close link between magnetic and lattice effects in these $\mathrm{R}_{2} \mathrm{Fe}_{17}$-based compounds. This behavior can be understood within the classical model of itinerant ferromagnetism in which the magnetovolume effect is related to the gradient of the density of states (DOS) at the Fermi level $\mathrm{E}_{\mathrm{F}}$. If $\mathrm{E}_{\mathrm{F}}$ lies in an energy region with a steep slope of the DOS curve, small changes in the position of $\mathrm{E}_{\mathrm{F}}$ could induce large changes in the magnetic moment. Theoretical calculations for $\mathrm{R}_{2} \mathrm{Fe}_{17}$ ( $\mathrm{R}=\operatorname{Pr}$ and $\mathrm{Gd}$ ) (Ref. 15) show that the slope of the DOS curve at $\mathrm{E}_{\mathrm{F}}$ for $3 d$ and $4 p$ densities of states of $\mathrm{Fe}$ is indeed very steep, consistent with the above discussion.

We have extended the MCE investigations of $\mathrm{R}_{2} \mathrm{Fe}_{17^{-}}$ based compounds ${ }^{7}$ by measurement of the MCE values for $\mathrm{Ho}_{2} \mathrm{Fe}_{17-\mathrm{x}} \mathrm{Mn}_{\mathrm{x}}$. Figure 4(a) shows the $M$ versus $\mu_{0} H$ curves for the magnetic regions of interest around $\mathrm{T}_{\mathrm{C}}$ for $\mathrm{Ho}_{2} \mathrm{Fe}_{17}$ as a representative example. The corresponding Arrott plots of $M^{2}$ versus $\mu_{0} H / M$ are shown in Fig. 4(b). The positive slopes in the isotherm Arrott plots indicate the second-order nature of the phase transition around $\mathrm{T}_{\mathrm{C}}$ for $\mathrm{Ho}_{2} \mathrm{Fe}_{17}$. The values of the magnetic entropy change $\Delta \mathrm{S}$ have been obtained from the Maxwell relation, ${ }^{7}$

$$
-\Delta S_{M}(T, H)=\mu_{0} \int_{0}^{H}\left(\frac{\partial M}{\partial T}\right)_{H} d H .
$$

The magnetic entropy changes of $\mathrm{Ho}_{2} \mathrm{Fe}_{17}$ as a function of temperature and change in external field are shown in Fig. 4(c) with the maximum of $-\Delta \mathrm{S}$ derived to be $1.1 \mathrm{~J} \mathrm{~kg}^{-1} \mathrm{~K}^{-1}, 1.8 \mathrm{~J}$ $\mathrm{kg}^{-1} \mathrm{~K}^{-1}, 2.4 \mathrm{~J} \mathrm{~kg}^{-1} \mathrm{~K}^{-1}, 2.8 \mathrm{~J} \mathrm{~kg}^{-1} \mathrm{~K}^{-1}$, and $3.2 \mathrm{~J} \mathrm{~kg}^{-1}$ $\mathrm{K}^{-1}$, for external field changes from 0 to $1 \mathrm{~T}, 0$ to $2 \mathrm{~T}, 0$ to 3 $\mathrm{T}, 0$ to $4 \mathrm{~T}$, and 0 to $5 \mathrm{~T}$, respectively. Similar results have been obtained for $\mathrm{Ho}_{2} \mathrm{Fe}_{15} \mathrm{Mn}_{2}$, with MCE values $0.9 \mathrm{~J} \mathrm{~kg}^{-1}$ $\mathrm{K}^{-1}, 1.5 \mathrm{~J} \mathrm{~kg}^{-1} \mathrm{~K}^{-1}$, and $2.6 \mathrm{~J} \mathrm{~kg}^{-1} \mathrm{~K}^{-1}$ in the region of $\mathrm{T}_{\mathrm{C}} \sim 302 \mathrm{~K}$ for $\Delta \mathrm{B}=0-1 \mathrm{~T}, 0-2 \mathrm{~T}$, and 0-5 T, respectively.

\section{CONCLUSIONS}

Mn substitution for $\mathrm{Fe}$ in $\mathrm{Ho}_{2} \mathrm{Fe}_{17-\mathrm{x}} \mathrm{Mn}_{\mathrm{x}}$ leads to a minimum in the composition dependence of the spontaneous magnetization $\mathrm{M}_{\mathrm{s}}$ at $10 \mathrm{~K}$ around $\mathrm{Mn}$ content $\mathrm{x}=3.8$. Pronounced magnetovolume effects have been observed below the magnetic ordering temperatures; this leads to Invar-type behavior which can be linked to the character of the density of states of $\mathrm{Fe}$ atoms. With a magnetic field change of $0-5 \mathrm{~T}$, the magnetic entropy change around $T_{C}$ has been found to be $3.2 \mathrm{~J} \mathrm{~kg}^{-1} \mathrm{~K}^{-1}$ and $2.7 \mathrm{~J} \mathrm{~kg}^{-1} \mathrm{~K}^{-1}$ for $\mathrm{Ho}_{2} \mathrm{Fe}_{17}\left(T_{\mathrm{C}} \sim 336 \mathrm{~K}\right)$ and $\mathrm{Ho}_{2} \mathrm{Fe}_{15} \mathrm{Mn}_{2}\left(T_{\mathrm{C}} \sim 302 \mathrm{~K}\right)$, respectively.

${ }^{1}$ Y. M. Hao et al., Appl. Phys. Lett. 78, 3277 (2001).

${ }^{2}$ A. V. Lukoyanov et al., Phys. Rev. B 80, 104409 (2009).

${ }^{3}$ J. Stankiewicz et al., Phys. Rev. B 83, 014419 (2011).

${ }^{4}$ P. C. Ezekwenna et al., J. Appl. Phys. 81, 4533 (1997).

${ }^{5}$ J. L. Wang et al., Phys. Rev. B 75, 174423 (2007).

${ }^{6}$ A. E. Teplykh et al., Phys. Solid State 52, 922 (2010).

${ }^{7}$ K. Mandal et al., J. Phys. D: Appl. Phys. 37, 2628 (2004); H. Y Chen et al., J. Magn. Magn. Mater. 320, 1382 (2008).

${ }^{8}$ J. L. Wang et al., J. Phys.: Conf. Ser. 200, 082025 (2010).

${ }^{9}$ A. J. Studer et al., Physica B 385-386, 1013 (2006).

${ }^{10}$ Y. G. Wang et al., J. Appl. Phys. 84, 6229 (1998).

${ }^{11}$ J. L. Wang et al., J. Appl. Phys. 92, 1453 (2002).

${ }^{12} \mathrm{~J}$. L. Wang et al., "Effect of Mn substitution for Fe on the structural and magnetic properties of $\mathrm{Ho}_{2} \mathrm{Fe}_{17}$ " (unpublished).

${ }^{13}$ J. Kamarád et al., J. Appl. Phys. 85, 4874 (1999).

${ }^{14}$ D. Givord, F. Givord, and R. Lemaire, J. Phys. Colloq. 32, 1 (1971).

${ }^{15}$ Yu. V. Knyazev et al., Phys. Rev. B 73, 094410 (2006). 